\title{
Similarities and Differences of International Practices and Procedures for the Regulation for Active Substance Master Files/Drug Master Files of Human Use: Moving Toward Regulatory Convergence
}

\author{
Maki Matsuhama, Tomoko Takishita, Ryosuke Kuribayashi, Kazunori Takagi, Rika Wakao, and Kenichi Mikami \\ Office of Generic Drugs, Pharmaceuticals and Medical Devices Agency, Tokyo, Japan
}

Received, January 14, 2016; Revised, May 22, 2016; Accepted, July 29, 2016; Published, August 5, 2016

\begin{abstract}
Purpose. A gap analysis survey of international practices for Active Substance Master Files (ASMFs)/Drug Master Files (DMFs) of human use was conducted as a project of the ASMF/DMF working group of the International Generic Drug Regulators Pilot (IGDRP) to identify similarities and differences among ASMF/DMF procedures of 10 IGDRP members and 2 observers. Methods. We conducted a questionnaire survey and compared the following aspects: overall ASMF/DMF procedures, submission requirements for ASMFs/DMFs, assessment processes for ASMFs/DMFs, the technical requirements for active pharmaceutical ingredients (APIs), generation of assessment reports for ASMFs/DMFs, procedures for changing ASMF/DMF details, and Good Manufacturing Practice (GMP) inspection/certification of API manufacturers. Twelve organizations participated in this project: the Brazilian Health Surveillance Agency (Anvisa), the European Union (EU), Health Canada (HC), the Singapore Health Sciences Authority (HSA), the South African Medicines Control Council (MCC), the South Korean Ministry of Food and Drug Safety (MFDS), the Japanese Pharmaceuticals and Medical Devices Agency (PMDA), the Swiss Agency for Therapeutic Products (Swissmedic), the Taiwan Food and Drug Administration (TFDA), the Australian Therapeutic Goods Administration (TGA), the European Directorate for the Quality of Medicines \& HealthCare (EDQM) (Observer) and the Prequalification Team (PQT) of the World Health Organization (WHO), which includes the PQT-Medicines (Observer). Results. Although there were many similarities among the participating agencies surveyed, there were also differences that should be discussed such as assessment processes of ASMFs/DMFs and Technical requirements for APIs. Conclusions. These differences revealed by this survey will be key considerations in order to facilitate the filing of ASMFs/DMFs globally and to establish a framework for sharing and utilizing information related to ASMFs/DMFs among IGDRP members in the future.
\end{abstract}

This article is open to POST-PUBLICATION REVIEW. Registered readers (see "For Readers") may comment by clicking on ABSTRACT on the issue's contents page.

\section{INTRODUCTION}

Active Pharmaceutical Ingredients (APIs) are indispensable for manufacturing drug products. Their manufacture utilizes significant technical know-how, much of which is the intellectual property of the API manufacturer. For example, synthetic processes, reaction and purification conditions. Often manufacturing information is registered as patents $(1,2)$. It is important to API manufacturers to protect their intellectual property because it is directly linked to their business interests.

In the registration application for Marketing Authorizations (MA) of drug products, API quality data as well as drug product quality data are required. If an applicant of a drug product manufactures the API itself, the applicant is able to provide this API information directly to the regulatory agency together with other application data. However, APIs are generally manufactured by dedicated, third-party API manufacturers, not the drug product manufacturer. Thus, it is difficult for API manufacturers to provide their confidential information to the applicant in support of a drug product application. To protect the API manufacturer's confidential information, an Active Substance Master File (ASMF)/Drug Master File (DMF) system has been developed.

Correspondence Author: Maki Matsuhama; Office of Generic Drugs, Pharmaceuticals and Medical Devices Agency, 3-3-2, Kasumigaseki, Chiyoda-ku, Tokyo 100-0013, Japan. Tel: +81-3-3506-9001; Fax: +81-3-3506-1104; E-mail: matsuhamamaki@pmda.go.jp. 
This system enables API information, including confidential intellectual property, to be provided to a regulatory agency by API manufacturers directly without disclosing protected information to the applicant. Typically, the API manufacturer submits this data to the regulatory agency in the form of an ASMF/DMF. The applicant can then refer to the ASMF/DMF data by providing a letter of access, which is consent by the ASMF/DMF holder to permit the regulatory agency to access the ASMF/DMF data to support the applicant's drug product submission. ASMF/DMF systems are utilized in many organizations.

Increasingly API supply chains are globalized $(3,4)$. API manufacturers export their APIs to various countries and applicants use multiple sources of APIs in order to secure a stable supply of generic drugs. Even when an API manufacturer supplies the same API to applicants in different countries, an assessment based on the regulations in each country is required. Therefore it is supposed that similar assessments are carried out by multiple regulatory agencies even when it is the same API, manufactured at the same manufacturing site, by the same manufacturing method. In order to avoid duplication of assessments, mutual collaboration procedures could be established under which one agency will assess the ASMF/DMF on behalf of other concerned agencies. Convergence of ASMF/DMF regulation will streamline the process of assessment and be beneficial for regulatory agencies, applicants and API manufacturers.

Against such a background, the International Generic Drug Regulators Pilot (IGDRP) was launched in 2012, and an ASMF/DMF working group has been established in the IGDRP. The scope of the ASMF/DMF working group is limited to APIs for human use that are the subject of master file assessments (5). This working group is working to establish a framework for information sharing and potential mutual reliance in the assessment of ASMFs/DMFs among the members. This activity will ultimately enable members to avoid unnecessary assessments and optimize the consistency of assessment outcomes.

In order to progress the IGDRP ASMF/DMF working group discussions, it was important to understand the similarities and differences of the ASMF/DMF regulation among the participating organizations. However, the survey that compared the ASMF/DMF system information of all 12 organizations has not been reported. Therefore, a gap analysis survey of the practices and procedures for ASMFs/DMFs was initiated in May 2014 by the Pharmaceuticals and Medical Devices Agency (PMDA), the regulatory agency in Japan. Twelve organizations participated in this project. In this article, we present the results of this survey as the first step toward understanding the current situation with a view to assist in guiding the work of the IGDRP ASMF/DMF working group for regulatory convergence in this area.

\section{METHODS}

Table 1 lists the 12 international organizations that participated in this survey, along with their corresponding regulatory agencies and their guidelines on ASMFs/DMFs.

A questionnaire of 84 questions relating to ASMF/DMF procedures was completed by each member. The information was evaluated by February 2015.

We compared similarities and differences in the treatment of ASMFs/DMFs during their lifecycle under the following topics:

1. An outline of ASMF/DMF systems

2. Submission requirements for ASMFs/DMFs

3. The assessment process for ASMFs/DMFs

4. The technical requirements for APIs

5. The generation of assessment reports for ASMFs/DMFs

6. Procedures for changing ASMF/DMF details

7. Good Manufacturing Practice (GMP) inspection/certification of API manufacturers

\section{RESULTS AND DISCUSSION}

\section{An Outline of ASMF/DMF Systems}

ASMF/DMF procedures are used by the Brazilian Health Surveillance Agency (Anvisa), the European Directorate for the Quality of Medicines \& HealthCare (EDQM), the European Union (EU), Health Canada (HC), the Singapore Health Sciences Authority (HSA), the South Korean Ministry of Food and Drug Safety (MFDS), the PMDA, the Prequalification Team (PQT) of the World Health Organization (WHO; PQT-WHO), the Swiss Agency for Therapeutic Products (Swissmedic), the 


\begin{tabular}{|c|c|c|}
\hline Organization & ASMF/DMF guideline referenced & Date posted \\
\hline $\begin{array}{l}\text { Brazilian Health Surveillance } \\
\text { Agency (Anvisa) }\end{array}$ & Resolution-RDC No. 57 (6) & $\begin{array}{l}\text { November } \\
2009\end{array}$ \\
\hline European Union (EU) & Guideline on Active Substance Master File Procedure (7) & May 2013 \\
\hline Health Canada (HC) & Drug Master Files (DMFs) (draft document) (8) & $\begin{array}{l}\text { September } \\
2008\end{array}$ \\
\hline Health Sciences Authority (HSA) & Guideline on Medicinal Product Registration in Singapore (9) & January 2014 \\
\hline Medicines Control Council (MCC) & - & - \\
\hline $\begin{array}{l}\text { Ministry of Food and Drug Safety } \\
\text { (MFDS) }\end{array}$ & $\begin{array}{l}\text { The drug registration system (DMF) handbook second edition } \\
\text { (commentary) (10) }\end{array}$ & $\begin{array}{l}\text { November } \\
2012\end{array}$ \\
\hline $\begin{array}{l}\text { Pharmaceuticals and Medical } \\
\text { Devices Agency (PMDA) }\end{array}$ & $\begin{array}{l}\text { Guideline on Utilization of Master File for Drug Substances, etc. } \\
\text { (11) }\end{array}$ & February 2005 \\
\hline $\begin{array}{l}\text { Swiss Agency for Therapeutic } \\
\text { Products (Swissmedic) }\end{array}$ & $\begin{array}{l}\text { Follows the EU Guideline on Active Substance Master File } \\
\text { Procedure, with annotations (12) }\end{array}$ & $\begin{array}{l}\text { September } \\
2014\end{array}$ \\
\hline $\begin{array}{l}\text { Taiwan Food and Drug } \\
\text { Administration (TFDA) }\end{array}$ & DMF Application Technical Information Checklist (13) & February 2013 \\
\hline $\begin{array}{l}\text { Therapeutic Goods Administration } \\
\text { (TGA) }\end{array}$ & $\begin{array}{l}\text { Follows the EU Guideline on Active Substance Master File } \\
\text { Procedure, with annotations (14) }\end{array}$ & August 2013 \\
\hline $\begin{array}{l}\text { European Directorate for the } \\
\text { Quality of Medicines and } \\
\text { HealthCare (EDQM) })^{a}\end{array}$ & $\begin{array}{l}\text { Content of the dossier for chemical purity and microbiological } \\
\text { quality (15) }\end{array}$ & $\begin{array}{l}\text { February } 2007 \\
\text { (under } \\
\text { revision) }\end{array}$ \\
\hline $\begin{array}{l}\text { Prequalification Team, World } \\
\text { Health Organization (PQT- } \\
\text { WHO) })^{a, b}\end{array}$ & $\begin{array}{l}\text { Guidelines on active pharmaceutical ingredient master file } \\
\text { procedure (16) } \\
\text { Guidelines on submission of documentation for a multisource } \\
\text { (generic) finished pharmaceutical product for the WHO } \\
\text { Prequalification of Medicines Programme: quality part (17) }\end{array}$ & 2008 \\
\hline \multicolumn{3}{|c|}{$\begin{array}{l}\boldsymbol{a} \text { The EDQM and the PQT-WHO are observers to the IGDRP. } \\
\boldsymbol{b} \text { The PQT is a unit within the WHO, which includes the Prequalification Team-Medicines. The primary function of the } \\
\text { Prequalification Team-Medicines is to determine if essential medicines intended for international procurement meet WHO } \\
\text { standards for quality, safety, and efficacy, and are produced under WHO GMP standards. } \\
\text { IGDRP, International Generic Drug Regulators Pilot. }\end{array}$} \\
\hline
\end{tabular}

Taiwan Food and Drug Administration (TFDA), and the Australian Therapeutic Goods Administration (TGA). The API master file (APIMF) procedure and API prequalification procedure of the PQT-WHO correspond to an ASMF/DMF system. API prequalification is a comprehensive evaluation that includes assessment of the APIMF to verify with WHO norms and standards, and assessment of sites of API manufacture to verify compliance with WHO GMP requirements (18). In the EDQM, the Certificate(s) of Suitability to the Monographs of the European Pharmacopoeia (CEPs) procedure also corresponds to an ASMF/DMF system. There is no ASMF/DMF system used by the MCC of the South African Medicines Control Council (MCC), but the MCC is currently developing an ASMF/DMF system.

All organizations permit the submission of master files for APIs. In addition, HC, the HSA, the PMDA and the TGA accept master files for API intermediates. Other than APIs and intermediates, master files for excipients can be submitted to the EDQM, HC, and the PMDA. Materials for medical devices are also the subject of master files within the PMDA.

The acceptance criteria for ASMFs/DMFs are different among the organizations. For example, HC accepts different polymorphic forms of an API in the same ASMF/DMF, whereas the other organizations do not. Additionally, in the case of differing synthetic routes (e.g., enzymatic versus synthetic only), the MFDS and the TFDA accepts differing synthetic routes as long as the final API specification is the same. The EDQM and HC do not recommend the inclusion of differing synthetic routes in the same ASMF/DMF, while the remaining organizations do not accept such situations. Knowledge of the acceptance criteria of the practices of other regulatory agencies is important (e.g., different forms of the API in the 
same ASMF/DMF) when comparing ASMFs/DMFs between agencies and when attempting to utilize assessment reports from other regulatory agencies.

In each organization, there is a coding system for ASMFs/DMFs to distinguish other ASMFs/DMFs. For example, the EDQM and HC apply a chronological coding 'YYYY-XXX' to received ASMFs/DMFs, where $Y$ is the received year and $\mathrm{X}$ is the number of ASMF/DMFs received so far for that year). Swissmedic applies the code 'DXXXXX ( $\mathrm{X}$ is a serial number)' to received ASMF/DMFs. The TGA has no internal coding system, TGA uses the code provided by the ASMF/DMF holder but gives the ASMF/DMF a TGA file number XXXX/yyyyy, where XXXX is the year when the ASMF/DMF was first submitted and any subsequent changes to the ASMF/DMF (updates), and yyyyy is a number given by the TGA. In all regulatory agencies, such internal codes do not change when the ASMF/DMF version is updated.

The use of an ASMF/DMF procedure is not mandatory except by the Anvisa and the MFDS. Anvisa requires the submission of an ASMF/DMF for 30 listed APIs, and the remaining APIs are evaluated with the drug product application. Anvisa expectation is to increase the number of APIs that must undergo the ASMF/DMF procedure in the following years. Similarly, the MFDS also requires registration on 206 APIs listed including their salts and hydrates and new chemical entities (NCEs) authorized by the MFDS after 1 July 2002 and updates on the list. Though the use of an ASMF/DMF procedure is not mandatory in TFDA, TFDA requires API registration of only NCEs and 10 other listed APIs. All organizations permit an unlimited number of ASMFs/DMFs to be submitted for the same API.

In some organizations, additional conditions are imposed when foreign companies submit ASMFs/DMFs, although the ASMFs/DMFs are submitted to regulatory agencies directly by the API manufacturers. Anvisa requires that a legal entity making a submission to the regulatory agency must be based in Brazil. The MFDS, PMDA, and TFDA require the appointment of an in-country caretaker or agent if the ASMF/DMF holder is a foreign company. In Japan and South Korea, in-country caretakers play important roles in administration procedures because ASMF/DMF application forms, notifications and other related documents have to be written in the native language (19). HC recommends that a North American agent is used in order to expedite communications if an ASMF/DMF Holder is not based in North America.

\section{Submission Requirements for ASMFs/DMFs}

All organizations require the submission of an administrative submission form with the ASMF/DMF. In addition, letters of access, GMP certification, bovine spongiform encephalopathy (BSE)/transmissible spongiform encephalopathy (TSE) certification, and fees are required in some organizations. A letter of access generally means a letter written by the ASMF/DMF holder permitting a regulatory agency to reference information in the ASMF/DMF on behalf of the applicant (8).

Most organizations have adopted the International Conference on Harmonization (ICH) of Technical Requirements for Registration of Pharmaceuticals for Human Use Common Technical Document (CTD) format as the structure for the technical document (with the exception of Anvisa). The MFDS and PMDA accept not only the CTD but also other formats. The CTD format is provided by the International Conference on Harmonization as a common format for the technical documentation (20). Table 2 shows the contents of CTD sections. In addition, the EDQM, the EU, HC, the PQT-WHO, and Swissmedic require submission of Module 2 of the CTD (quality overall summary (QOS)) for APIs.

The EU, HC, the HSA, the MFDS, the PMDA, the PQT-WHO (APIMF procedure), Swissmedic, and the TGA have adopted the division of ASMFs/DMFs into an Applicant's Part and a Restricted Part. For example, the EU guideline states that "the Applicant's Part contains the information that the ASMF holder regards as non-confidential to the applicant, whereas the Restricted Part contains the information that the ASMF holder regards as confidential" (7). The terms "Applicant's Part" and "Restricted Part" are interchangeable with the terms "Open Part" and "Closed Part", respectively, in some other organizations. The CTD subsections 3.2.S.2.23.2.S.2.6 (see Table 2) are the main components of the Restricted Part, with the remaining sections forming the Applicant's Part. The EU, HC and the PMDA prescribe the division of information between the Applicant's Part and the Restricted Part in their guidelines. 


\begin{tabular}{ll}
\hline \multicolumn{2}{l}{ Table 2. CTD module 3 sections/subsections } \\
\hline $\begin{array}{l}\text { CTD sections/ } \\
\text { subsections }\end{array}$ & Content \\
\hline 3.2.S.1 & General information \\
3.2.S.2 & Manufacture \\
3.2.S.2.1 & Manufacturer(s) \\
3.2.S.2.2 & Description of manufacturing process \\
& and process controls \\
3.2.S.2.3 & Control of materials \\
3.2.S.2.4 & Controls of critical steps and \\
& intermediates \\
3.2.S.2.5 & Process validation and/or evaluation \\
3.2.S.2.6 & Manufacturing process development \\
3.2.S.3 & Characterization \\
3.2.S.4 & Control of drug substance \\
3.2.S.5 & Reference standards or materials \\
3.2.S.6 & Container closure system \\
3.2.S.7 & Stability \\
\hline
\end{tabular}

CTD, common technical document

In the EMA study on MA applications, much deficiencies were found in the CTD section 3.2.S.2 and 3.2.S.4 (see Table 2) (21). In addition, WHO reported that the most deficiencies were observed in the CTD section 3.2.S.2, followed by 3.2.S.4 among APIMF submitted to WHO Prequalification of Medicines Programme (22). Our survey revealed that the API control section (3.2.S.4) is generally an Applicant's Part, and the most of API manufacturing section (3.2.S.2) is basically a Restricted Part in ASMFs/DMFs. Especially the Restricted Part is not disclosed to drug product applicants and it is prepared only by ASMF/DMF holders. In order to reduce deficiencies in the Restricted Part, different approaches by taking account of the Applicant's Part or Restricted Part might be effective, such as making guidance for ASMF/DMF holders that is specialized on the Restricted Part for ASMF/DMF holders. It might be necessary to discuss in collaboration with ASMF/DMF holders and regulatory agencies what kind of approaches are helpful.

\section{The Assessment Process for ASMFs/DMFs}

Based on the ASMFs/DMFs' relationship to a related drug product assessment process, ASMF/DMF assessment processes can be classified as follows:

- Group 1 (assessment process is in conjunction with a drug product assessment process): the $\mathrm{EU}, \mathrm{HC}$, the HSA, the PMDA, the PQT-WHO (APIMF procedure), Swissmedic, and the TGA
- Group 2 (assessment process is independent of a drug product assessment process): Anvisa, the EDQM, the MFDS, the PQT-WHO (API Prequalification), and the TFDA

The Group 1 organizations undertake the ASMF/DMF assessment process in conjunction with the drug product assessment process (i.e., the ASMF/DMF has been referenced in an application for a drug product). The drug product applicant, the ASMF/DMF holder and the regulatory agency are involved in the ASMF/DMF assessment process. All organizations in Group 1 adopt the Applicant's Part/Restricted Part structure. By adopting this structure, a regulatory agency is able to discuss with an applicant the nonproprietary information contained in the Applicant's Part, because the Applicant's Part is itself shared with the applicant. Table 3 shows the relationship among the ASMF/DMF holder, the regulatory agency, and the drug product applicant in the assessment process of the Applicant's Part. As shown in the Table 3, EU, $\mathrm{HC}$, the HSA, the PQT-WHO (APIMF procedure), and Swissmedic are provided not only both parts by the ASMF/DMF Holder, but also a copy of Applicant's Part by the drug product applicant. When deficiencies are found in the Applicant's Part, the EU, HC, the HSA and the TGA send deficiency letters to both the ASMF/DMF holder and the drug product applicant. On the other hand, the PMDA and Swissmedic send deficiency letters found in the Applicant's Part only to the applicant, and PQT-WHO (APIMF procedure) send letters only to the ASMF/DMF holder. All regulatory agencies receive responses from the ASMF/DMF holder. In addition, the EU, HC, the HSA, and Swissmedic receive responses from the drug product applicant. When the ASMF/DMF is accepted, it is accepted in connection with the MA of the drug product. At least in the EU, it is stipulated in guidelines that the marketing authorization holder (MAH) takes full responsibility for the quality and quality control of the API (7) and this may be the reason that an applicant is involved in all steps in the assessment process. It is supposed that the degree of involvement of an applicant in the assessment process for the ASMF/DMF is based on the concept of residence of responsibility for APIs in each organization. 


\begin{tabular}{|c|c|c|c|c|c|c|}
\hline \multirow[b]{2}{*}{ Organization } & \multicolumn{2}{|c|}{ Submission } & \multicolumn{2}{|c|}{$\begin{array}{c}\text { Deficiency letters on } \\
\text { Applicant's Part }\end{array}$} & \multicolumn{2}{|c|}{$\begin{array}{l}\text { Response to the deficiency } \\
\text { letters on Applicant's Part }\end{array}$} \\
\hline & $\begin{array}{l}\text { ASMF/DMF } \\
\text { holder submits both } \\
\text { of Applicant's Part } \\
\text { and Restricted Part. }\end{array}$ & $\begin{array}{c}\text { Applicant } \\
\text { submits a copy } \\
\text { of the } \\
\text { Applicant's } \\
\text { Part. }\end{array}$ & $\begin{array}{l}\text { ASMF/DMF } \\
\text { holder } \\
\text { receives } \\
\text { deficiency } \\
\text { letters. }\end{array}$ & $\begin{array}{l}\text { Applicant } \\
\text { receives } \\
\text { deficiency } \\
\text { letters. }\end{array}$ & $\begin{array}{l}\text { ASMF/DMF } \\
\text { holder } \\
\text { responds to } \\
\text { the deficiency } \\
\text { letters. }\end{array}$ & $\begin{array}{l}\text { Applicant } \\
\text { responds to } \\
\text { the deficiency } \\
\text { letters. }\end{array}$ \\
\hline EU & 0 & 0 & 0 & 0 & 0 & 0 \\
\hline $\mathrm{HC}$ & 0 & o & 0 & o & 0 & O \\
\hline HSA & 0 & 0 & 0 & 0 & 0 & 0 \\
\hline PMDA & o & & & o & o & \\
\hline $\begin{array}{l}\text { PQT-WHO } \\
\text { (APIMF } \\
\text { procedure) }\end{array}$ & o & O & o & & ○ & \\
\hline Swissmedic & 0 & O & & 0 & 0 & 0 \\
\hline TGA & $\circ$ & & O & O & 0 & \\
\hline
\end{tabular}

Anvisa, EDQM, MFDS, PQT-WHO (API prequalification), and TFDA are not listed because they assess ASMF/DMF independent of a drug product.

The Group 2 organizations undertake the ASMF/DMF assessment process independent of the drug product assessment process. All assessment processes are completed between the ASMF/DMF holder or in-country caretaker and the regulatory agency, except for Anvisa where the assessment process is undertaken between the applicant (e.g. the drug product applicant or the legal entity) which is responsible for the ASMF/DMF application and the regulatory agency. For example, the ASMF/DMF holder submits an ASMF/DMF to the regulatory agency, receives deficiency letters from the regulatory agency and responds to the regulatory agency. After these processes, the ASMF/DMF is accepted on its own.

Table 4 shows information about the application fee and assessment period of the ASMF/DMF. Within the Group 1 organizations discussed above, an application fee for the assessments of ASMFs/DMFs is not charged because it is part of the drug product application fee. $\mathrm{HC}$ has an additional nominal fee for the administration of ASMFs/DMFs. In the Group 2, an application fee for the ASMF/DMF is charged, except for Anvisa.

Table 4 also summarizes the assessment timelines for the new ASMFs/DMFs application, excluding the time to submit responses. The EDQM, the MFDS, and the TFDA have assessment periods for the ASMF/DMF itself. The EU, HC, the HSA, the PMDA, Swissmedic, and the TGA have assessment periods for the ASMF/DMF that are determined by the timeline for the drug product assessment period. Anvisa has no limit for the ASMF/DMF assessment period.

When a drug product application (that is linked to the ASMF/DMF) is rejected or withdrawn before acceptance of the ASMF/DMF, the EU, HC, the HSA, the PMDA, the PQT-WHO, and Swissmedic suspend assessment of the ASMF/DMF. On the other hand, Anvisa, the TFDA, and the TGA continue assessment of the ASMF/DMF.

\section{The Technical Requirements for APIs}

Table 5 shows the pharmacopeias officially recognized and the acceptance of the EDQM's CEPs by various agencies. The European Pharmacopoeia ( $\mathrm{Ph}$. Eur.) is the most widely accepted pharmacopeia within the participating agencies.

Table 6 shows the reference guidelines to control the quality of APIs in each organization. ICH guidelines (23) are widely referred to by participating agencies with respect to starting materials, impurities, and stability testing. In addition, the Committee for Medicinal Products for Human Use (CHMP) guidelines (24) are referred to by some agencies regarding starting materials and impurities.

All organizations require the stability testing of APIs. According to the EU guidelines for stability of existing substances, an API that is covered by a $\mathrm{Ph}$. Eur. monograph (where degradation products are listed), the EU does not require stability testing 
as long as the API is tested immediately before use. The PMDA does not require to submit results of stability testing of API as document of approval application of generic drug products in general. If the stability of an API cannot be assumed from the originator (e.g., polymorphic form difference, hydrate difference), the PMDA requires to submit results of stability testing of API in the assessment process in the case of approval application of generic drug. For the EDQM CEP procedure, a retest period is optional (according to EU rules), but in practice stability data are generally submitted and many CEPs carry a retest period.

Several organizations require specific stability study conditions (e.g., due to climatic zone conditions). For example, Anvisa requires studies to be conducted under the conditions indicated by the domestic guideline (25). Although the MCC refers to the ICH guideline as the primary requirement (26), they also require specific conditions if the API is temperature sensitive. Similarly, although the PQT-WHO follows the ICH guideline, PQT-WHO has its own guideline (17) and stipulates a first preference for long-term stability testing at Zone $\mathrm{IVb}$ conditions.

\section{The Generation of Assessment Reports for ASMFs/DMFs}

Table 7 shows the similarities and differences of the procedures related to ASMF/DMF assessment reports. All organizations generate assessment reports for ASMFs/DMFs. However, the PMDA doesn't generate assessment reports for ASMFs/DMFs submitted in support of generic drug products. Though PMDA generates reports only in the case of new drug products, the PMDA is considering generating assessment reports for ASMFs/DMFs supporting generic drug products. All members adopt a descriptive assessment report style.

Table 4. Assessment periods and application fees for new ASMFs/DMFs

\begin{tabular}{|c|c|c|c|}
\hline Group & Organization & $\begin{array}{l}\text { Application fee for ASMF/DMF } \\
\text { (excluding the case of variation } \\
\text { submissions) }\end{array}$ & $\begin{array}{l}\text { Assessment period of ASMF/DMF } \\
\text { (excluding the time to submit } \\
\text { responses; in calendar days, unless } \\
\text { otherwise specified) }\end{array}$ \\
\hline \multirow{7}{*}{$\begin{array}{l}\text { 1. Assessment } \\
\text { process in } \\
\text { conjunction } \\
\text { with a drug } \\
\text { product } \\
\text { assessment } \\
\text { process. }\end{array}$} & EU & No fee & $\begin{array}{l}210 \text { days (initial MA application) } \\
90 \text { days (MA variation application) }\end{array}$ \\
\hline & $\mathrm{HC}$ & 416 CAD (administration costs only) & $\begin{array}{l}180 \text { days (if referenced in an } \\
\text { Abbreviated New Drug (generic) } \\
\text { Submission) } \\
300 \text { days (if referenced in a New Drug } \\
\text { Submission) }\end{array}$ \\
\hline & HSA & No fee & 336 days (240 working days) \\
\hline & PMDA & No fee & $\begin{array}{l}210 \text { days } \\
\text { (This is approximate period, because } \\
\text { the response time of ASMF/DMF is not } \\
\text { prescribed definitely) }\end{array}$ \\
\hline & $\begin{array}{l}\text { PQT-WHO } \\
\text { (APIMF } \\
\text { procedure) }\end{array}$ & No fee & No limit (but change soon) \\
\hline & Swissmedic & No fee & Maximal 300 days \\
\hline & TGA & No fee & 210 days \\
\hline \multirow{5}{*}{$\begin{array}{l}\text { 2. Assessment } \\
\text { process } \\
\text { independent of } \\
\text { a drug product } \\
\text { assessment } \\
\text { process. }\end{array}$} & Anvisa & No fee & No limit \\
\hline & EDQM & 3000 Euros & 270 days \\
\hline & MFDS & $\begin{array}{l}460 \text { USD (electronically) } \\
510 \text { USD (paper) }\end{array}$ & 120 days \\
\hline & $\begin{array}{l}\text { PQT-WHO } \\
\text { (API } \\
\text { prequalification) }\end{array}$ & $\begin{array}{l}\text { Tiered fee structure } \\
\text { (covering assessment and inspection) } \\
\text { The first application: no fee } \\
\text { The second application: } 3000 \text { USD } \\
\text { The third application: } 6000 \text { USD } \\
\text { The forth or later application: } 8000 \text { USD }\end{array}$ & No limit (but change soon) \\
\hline & TFDA & 50 USD (2000 USD, since July 2015) & 180 days \\
\hline
\end{tabular}

MA, marketing authorization. 


\begin{tabular}{|c|c|c|c|c|c|c|}
\hline Organization & Ph. Eur. & USP & $\mathrm{BP}$ & JP & Ph. Int. & CEPs \\
\hline Anvisa & 0 & 0 & 0 & 0 & 0 & \\
\hline EDQM & 0 & & & & & \\
\hline $\mathrm{EU}^{a}$ & 0 & & & & & ○ \\
\hline $\mathrm{HC}$ & 0 & O & O & & 0 & 0 \\
\hline HSA & o & O & O & 0 & & o \\
\hline $\mathrm{MCC}$ & O & O & O & O & 0 & O \\
\hline MFDS & 0 & 0 & 0 & 0 & & \\
\hline PMDA & $\mathrm{o}^{b}$ & $\mathrm{O}^{b}$ & & 0 & & \\
\hline PQT-WHO & 0 & 0 & 0 & 0 & 0 & 0 \\
\hline Swissmedic & 0 & & & & & 0 \\
\hline TFDA & 0 & ○ & 0 & O & O & 0 \\
\hline TGA & 0 & $\circ$ & O & & & o \\
\hline
\end{tabular}

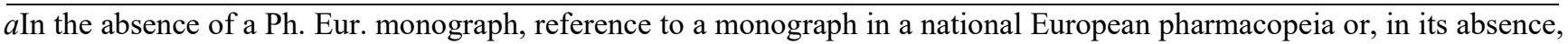
to a third country pharmacopeia can be accepted.

$b$ Only in the case of submission as an ASMF/DMF. The suitability of the Ph. Eur. and USP monograph as specification is evaluated during assessment. When a monograph is listed in JP, the specification should be conformance to the JP monograph before it is used for manufacturing drug products.

BP, British Pharmacopoeia; JP, Japanese Pharmacopoeia; Ph. Eur., European Pharmacopoeia; Ph. Int., International Pharmacopoeia; USP, United States Pharmacopeia.

Table 6. Reference guideline to control quality of APIs

\begin{tabular}{|c|c|c|c|c|c|c|}
\hline \multirow[b]{2}{*}{ Organization } & \multicolumn{2}{|c|}{ Starting Material } & \multicolumn{2}{|c|}{ Impurities } & \multicolumn{2}{|c|}{ Stability Testing } \\
\hline & ICH guideline & $\begin{array}{c}\text { CHMP } \\
\text { guideline }\end{array}$ & ICH guideline & $\begin{array}{l}\text { CHMP } \\
\text { guideline }\end{array}$ & ICH guideline & $\begin{array}{c}\text { Other } \\
\text { guideline }\end{array}$ \\
\hline Anvisa & 0 & & 0 & & & 0 \\
\hline EDQM & 0 & O & O & O & O & \\
\hline EU & O & o & O & o & o & \\
\hline $\mathrm{HC}$ & O & & 0 & & 0 & \\
\hline HSA & o & & O & & O & \\
\hline $\mathrm{MCC}$ & 0 & & O & & $\mathrm{O}^{a}$ & \\
\hline MFDS & O & & 0 & & 0 & \\
\hline PMDA & o & & o & & O & \\
\hline PQT-WHO & O & & O & 0 & $\mathrm{O}^{a}$ & \\
\hline Swissmedic & o & ○ & O & o & O & \\
\hline TFDA & O & O & O & O & O & \\
\hline TGA & 0 & & 0 & 0 & 0 & \\
\hline
\end{tabular}

Except for Anvisa, the MFDS, and the PMDA, assessment reports for ASMFs/DMFs are in English.

No member publishes their ASMF/DMF assessment reports, except in the case of new drugs by the PMDA and the TFDA. The EU includes an evaluation of the API in their public assessment reports of the drug product.

The EU, and Swissmedic (on request only for applications filed after 1 July 2015) provide copies of the ASMF/DMF assessment reports on the Applicant's Part to Applicants/MAHs. The EU also provides copies of the full ASMF/DMF assessment report (the Applicant's Part and the Restricted Part) to the ASMF/DMF holder.

6. Procedures for Changing ASMF/DMF Details When changes occur to the details of an ASMF/DMF, all organizations require for the ASMF/DMF holder to inform the regulatory authority of these changes. Like the initial assessment process, the timing of changeassessments can be classified into two patterns. One of the patterns is at the time of the filing of the 
updated information to the ASMF/DMF, another pattern is at the time the updated information is referenced in conjunction with a drug product application.

There are often different categories assigned to changes in the ASMF/DMF procedures of agencies (typically based on risk principles). For example, the EU has three types of change categories: Type IA (notification), Type IB (minor variations), and Type II (major variations). The MFDS and the PMDA have two types: partial change approval application and minor change notification. The PQT-WHO has four types: major amendments, minor amendments, immediate notification, and annual notification. The EDQM has three types: major change, minor change, and notifications. Anvisa is under discussion on the procedure. In addition, Anvisa, HC, the MFDS, the TFDA, and the PQT-WHO require periodic updates of ASMFs/DMFs. The MFDS requires it every year. $\mathrm{HC}$ and the PQT-WHO require this every 2 years. Anvisa and the TFDA require updates every 5 years. The EDQM requires one renewal after 5 years. Because the reporting categories are different among each organization, further investigations of their details such as documentation would be of value.

\section{GMP Inspection/Certification of API Manufacturers}

The TGA, Anvisa, the PMDA, the MFDS, and the PQT-WHO require the GMP certification of APIs manufacturers. HC has recently implemented this condition and is also moving toward this requirement. The timing of the demonstration of GMP certification varies in each organization. For example, Anvisa requires GMP evidence at the time of ASMF/DMF submission. The MFDS and the PQT-WHO require GMP to be established by the completion of ASMF/DMF assessment. The TGA and the PMDA require GMP to be established by the time of the drug product authorization. An application requesting GMP inspection is submitted by API manufacturers in HC and PQT-WHO, but by the drug product applicant in the TGA and the PMDA. Anvisa requires that the applicant of the ASMF/DMF requests GMP inspection of the API manufacturer.

Although GMP certification is not mandatory in the EU, the HSA, the MCC, Swissmedic, the TFDA and the EDQM, the EU and Swissmedic do require a GMP statement by a qualified person. In the EDQM, the API manufacturer has to declare compliance with the EU GMP Part II, inspections are carried out by the EDQM based on risk. The TFDA will require GMP certification for ASMF/DMF authorizations by 2016 .

Table 7. Similarities and differences in assessment report among participating organizations

\begin{tabular}{|c|c|c|c|}
\hline Organization & $\begin{array}{l}\text { There are assessment } \\
\text { reports of generic drug } \\
\text { product application }\end{array}$ & $\begin{array}{l}\text { There are assessment } \\
\text { reports of ASMF/DMF }\end{array}$ & $\begin{array}{c}\text { There are English } \\
\text { version assessment } \\
\text { reports of ASMF/DMF }\end{array}$ \\
\hline
\end{tabular}

Assessment reports of the Applicant's Part of the ASMF/DMF are provided to Applicant/MAH

\begin{tabular}{|c|c|c|c|c|}
\hline Anvisa & O & 0 & & \\
\hline EDQM & & 0 & ○ & $\mathrm{O}^{b}$ \\
\hline EU & 0 & O & ○ & 0 \\
\hline $\mathrm{HC}$ & 0 & 0 & 0 & \\
\hline HSA & 0 & 0 & 0 & \\
\hline $\mathrm{MCC}$ & o & & & \\
\hline MFDS & 0 & 0 & & \\
\hline PMDA & & $\mathrm{O}^{a}$ & & \\
\hline PQT-WHO & O & 0 & O & \\
\hline Swissmedic & 0 & 0 & 0 & $\mathrm{O}^{b}$ \\
\hline TFDA & 0 & 0 & 0 & \\
\hline TGA & 0 & $\circ$ & O & \\
\hline
\end{tabular}

$a$ Only in the case of new drug products.

$b$ On request only.

$\mathrm{MAH}$, marketing authorization holder. 


\section{CONCLUSION}

ASMF/DMF systems are widespread internationally and ASMFs/DMFs are assessed in many organizations. We conducted a gap analysis survey of ASMF/DMF procedures among IGDRP members and observers and identified similarities and differences between agencies participating in this survey.

First, the general acceptance criteria of different forms of an API in the same ASMF/DMF are largely the same, but there are differences in how agencies treat intermediates and these different forms (see 1. Outline of ASMF/DMF Systems). Second, the assessment processes of ASMFs/DMFs can be classified into two groups based on their relationship to the assessment process of an associated drug product (see 3. The Assessment Processes for ASMFs/DMFs). If the ASMF/DMF assessment process is conducted in conjunction with a drug product application, the Applicant's Part/Restricted Part structure is adopted for the technical document. Third, there are differences in the number and type of officially recognized pharmacopeias and guidelines for API quality among agencies (see 4. The Technical Requirements for APIs). Finally, there are various procedures to deal with ASMF/DMF changes in each organization (see 6. Procedures for Changing ASMF/DMF Details).

In order to progress to greater information sharing, regulatory convergence of technical requirements, and potentially mutual reliance of ASMF/DMF assessments, these differences will be key considerations. This survey is the first article to present and compare ASMF/DMF systems and ASMF/DMF assessment worldwide. We expect that further discussion will be undertaken to understand more deeply the current situation of ASMF/DMF systems and ASMF/DMF assessments worldwide.

\section{DISCLAIMER}

The views expressed in this article are those of the authors and do not necessarily reflect the official views of the Pharmaceuticals and Medical Devices Agency.

\section{ACKNOWLEDGMENTS}

The authors wish to thank the following for valuable contributions to this manuscript: Ana
Carolina Moreira Marino Araujo of the Anvisa, Hélène Bruguera of the EDQM, Paul Marshall of the EU, Gary Condran of HC, David Woo of the HSA, Silverani Padayachee of the MCC, Jiye Kim of the MFDS, Richard N. Weissmahr of the Swissmedic, Chiung-Ho Liao of the TFDA, Mariana Gebara-Coghlan of the TGA, Antony Fake of the WHO, and IGDRP members.

\section{REFERENCES}

1. Juerg Zimmermann BS, Hans Michael Buerger. Crystal modification of a n-phenyl-2pyrimidineamine derivative, processes for its manufacture and its use, 1999. WO/1999/003854.

2. Ari Ayalon ML, Revital Lifshitz, Valerie Niddam, Sofia Roytblat. Polymorphic form of atorvastatin calcium, 2001. WO/2001/036384.

3. Mizuho Information \& Research Institute. Report on the Project of Industrial development of the generic drugs and securing of stable supply, 2014. http://www.mhlw.go.jp/file/06-Seisakujouhou10800000-Iseikyoku/0000096678.pdf Accessed 14 Jan 2016, in Japanese.

4. Bennett S. China's growing presence in the global supply chain. chimica oggi/Chemistry Today. 2012; 30(1): 56-8.

5. Ward M. The International Generic Drug Regulators Pilot. WHO Drug Information. 2014; 28(1): 3-10.

6. Ministry of Health National Health Surveillance Agency. Resolution - RDC No.57, 2009, http://portal.anvisa.gov.br/wps/wcm/connect/7f624f 8046fea039ba0abb41cdd33a01/RDC+572009+\%28English\%29.pdf?MOD=AJPERES Accessed 22 June 2015.

7. European Medicines Agency (EMA). Committee of Human Medicinal Products (CHMP), Committee of Veterinary Medicinal Products (CVMP). Guideline on Active Substance Master File Procedure, 2013. http://www.ema.europa.eu/docs/en_GB/document_li brary/Scientific_guideline/2012/07/WC500129994.p df Accessed 13 Feb 2015.

8. Health Canada. Draft Guidance Document - Drug Master Files (DMFs), 2008. http://www.hcsc.gc.ca/dhp-mps/alt_formats/hpfbdgpsa/pdf/prodpharma/draft_ebauche_dmf_fmm_gu ide_ld-eng.pdf Accessed 13 Feb 2015.

9. Health Sciences Authority (HSA). Guideline on medicinal product registration in Singapore (April 2011) update, 2014. http://www.hsa.gov.sg/content/ hsa/en/Health_Products_Regulation/Western_Medic ines/Overview/Guidelines_on_Drug_Registration.ht ml Accessed 13 Feb 2015.

10. Ministry of Food and Drug Safety (MFDS). The drug registration system (DMF) handbook second edition (commentary), 2012. 
http://www.mfds.go.kr/index.do? $\mathrm{x}=0$ \&searchkey=tit le:contents\&mid=1161\&searchword=원료의약품 \& $\mathrm{y}=0 \&$ page $\mathrm{No}=1 \& \mathrm{seq}=5706 \& \mathrm{cmd}=\mathrm{V}$ Accessed 13 Feb 2015, in Korean.

11. Director of Evaluation and Licensing Division Pharmaceutical and Food Safety Bureau, Ministry of Health, Labour and Welfare (MHLW). Guideline on Utilization of Master File for Drug Substances, etc., 2005. http://www.pmda.go.jp/files/000153843.pdf Accessed 14 Jan 2016.

12. Swiss Agency for Therapeutic Products (Swissmedic). Instruction Authorisation of human medicines with known active pharmaceutical ingredients

https://www.swissmedic.ch/zulassungen/00153/0018 9/01878/index.html?lang=en Accessed 26 Feb 2015.

13. Taiwan Food and Drug Administration (TFDA). DMF Application Technical Information Checklist, 2013.

http://regulation.cde.org.tw/data/downloadfile.php?s id=946 Accessed 27 July 2015, in Taiwanese.

14. Australian Government, Department of Health and Ageing, Therapeutic Goods Administration (TGA). Guidance 11: Drug Master Files and Certificates of Suitability of a Monograph of the European Pharmacopoeia for drug substances, 2013. https://www.tga.gov.au/guidance-11-drug-masterfiles-and-certificates-suitability-monographeuropean-pharmacopoeia-drug-substances Accessed 13 Feb 2015.

15. European Directorate for the Quality of Medicines and HealthCare (EDQM). Content of the dossier for chemical purity and mincrobiological quality, https://www.edqm.eu/medias/fichiers/cep_content_o f_the_dossier_for_chemical_purity_mic.pdf Accessed 22 June 2015.

16. World Health Organization (WHO). Guidelines on active pharmaceutical ingredient master file procedure. WHO Technical Report Series, No 948, 2008.

17. World Health Organization (WHO). Guidelines on submission of documentation for a multisource (generic) finished pharmaceutical product for the WHO Prequalification of Medicines Programme: quality part, 2012. http://apps.who.int/prequal/info_general/documents/ TRS970/TRS_970-Annex4.pdf Accessed 26 Feb 2015.

18. World Health Organization (WHO). An introduction to the Prequalification of Active Pharmaceutical
Ingredients, http://apps.who.int/prequal/default.htm Accessed 9 May 2015.

19. Pharmaceuticals and Medical Devices Agency (PMDA). Master File System for Drug Substances, etc., http://www.pmda.go.jp/files/000153373.pdf Accessed 14 Jan 2016.

20. International Conference on Harmonisation of Technical Requirements for Registration of Pharmaceuticals for Human Use (ICH). ICH harmonised tripartite guideline: the common technical document for the registration of pharmaceuticals for human use: quality - M4Q(R1), 2002.

http://www.ich.org/fileadmin/Public Web Site/ICH _Products/CTD/M4_R1_Quality/M4Q_R__.pdf Accessed 18 May 2016.

21. Borg JJ, Robert JL, Wade G, et al. Where is industry getting it wrong? A review of quality concerns raised at day 120 by the committee for medicinal products for human use during European Centralised Marketing Authorisation Submissions for chemical entity medicinal products. J Pharm Pharm Sci, 2009; 12(2): 181-198.

22. Diego IO, Fake A, Stahl M, et al. Review of quality deficiencies found in active pharmaceutical ingredient master files submitted to the WHO Prequalification of Medicines Programme. J Pharm Pharm Sci, 2014; 17(2): 169-186.

23. International Conference on Harmonisation of Technical Requirements for Registration of Pharmaceuticals for Human Use (ICH). Quality Guidelines.

http://www.ich.org/products/guidelines/quality/articl e/quality-guidelines.html Accessed 1 June 2015.

24. Committee for Medicinal Products for Human Use (CHMP). Quality Guidelines, http://www.ema.europa.eu/ema/index.jsp?curl=page s/regulation/general/general_content_000081.jsp\&m id=WC0b01ac0580027546 Accessed 1 June 2015.

25. Ministry of Health National Health Surveillance Agency. RESOLUTION - RDC No. 45, 2012. http://bvsms.saude.gov.br/bvs/saudelegis/anvisa/201 2/rdc0045_09_08_2012.html Accessed 27 Feb 2015. in Portuguese

26. Medicines Control Council (MCC). Pharmaceutical and analytical CTD /eCTD, http://www.mccza.com/genericDocuments/2.25_PA _CTD_Aug14_v4_showing_changes.pdf Accessed 2 March 2015. 